\title{
The $d t x R$ Gene: A New Alternative Marker to Identify Corynebacterium ulcerans and Corynebacterium pseudotuberculosis by PCR Assay
}

\author{
Sunarno*, Nyoman Fitri, Maratu Soleha, Nelly Puspandari, Kambang Sariadji \\ Research and Development Center for Biomedical and Basic Technology of Health, National Institute of Health Research and Development, \\ J1. Percetakan Negara 29, Jakarta 10560, Indonesia \\ ${ }^{*}$ Corresponding author. E-mail: no_nar@yahoo.com
}

Received date: Nov 15, 2017; Revised date: Jun 6, 2018; Accepted date: Jul 12, 2018

\section{Abstract}

B ACKGROUND: There are found some studies which reported the successfull of polymerase chain reaction (PCR) assay to identify Corynebacterium ulcerans and Corynebacterium pseudotuberculosis. This study aimed to describe the $d t x R$ gene profile as a new marker for C. ulceran and C. pseudotuberculosis for the PCR assay.

METHODS: Ten C. ulcerans and 35 C. pseudotuberculosis DNA sequences data registered in GeneBank was analyzed by bioinformatic tools. PCR primer was designed based on the concerved region and the gene similarity data. On the other hands, reference strains (C. ulcerans NCTC 12077 and Corynebacterium diphtheriae NCTC 3984) and $d t x R$ gene of C. pseudotuberculosis (synthetic gene) were used

\section{Introduction}

Corynebacterium ulcerans and Corynebacterium pseudotuberculosis have a very close relationship based on similarity of $16 \mathrm{~S} r R N A$ and $r p o B$ genes, although both show slightly different clinical characteristics.(1) The concerns to C. ulcerans infections is increasing along with the increasing case of human infection which is associated with zoonotic transmission. (2,3) C. ulcerans has been found in many kinds of animals e.g., macaque, dog, ferret, cat, and water rat, either with or without clinical characteristics of the disease.(1,4-7) These animals are considered to be the in the PCR assay optimization for C. ulcerans and $C$. pseudotuberculosis identification.

RESULTS: The study showed that $d t x R$ genes of both $C$. ulcerans and C. pseudotuberculosis were more conserve than pld gene, moreover $d t x R$ gene was more specific compared to $16 \mathrm{~S}$ rRNA gene. PCR assay with $d t x R$ gene as a target could identify C. ulcerans and C. pseudotuberculosis accurately without mispriming, misamplification and misidentification.

CONCLUSION: $d t x R$ gene could be used as marker to identify $C$. ulcerans and $C$. pseudotuberculosis by PCR assay.

KEYWORDS: C. pseudotuberculosis, C. ulcerans, $d t x R$ gene, PCR

Indones Biomed J. 2018; 10(3): 236-42 reservoir that may threaten human health. It is stated that the animals which act as the reservoir of $C$. ulcerans. $(8,9)$ The concerns to C. pseudotuberculosis infections are generally linked to economy impact of the caseous lymphadenitis (CLA) cases in sheeps and goats. The prevalence of CLA among goat in some studies show a fairly high number (more than 20\%).(10-12) C.pseudotuberculosis is also found in camels (13), buffaloes (14), pigs (15) and humans (16). C. pseudotuberculosis potentially causes disease in humans through zoonotic transmission as well as $C$. ulcerans, though the incident is rare.(17)

C. ulcerans and C. pseudotuberculosis are important because they potentially to become pathogen for their 
capability to survive within macrophage as well as decreasing its' viability, consequently the immune system will be difficult to eliminate the bacteria. $(18,19)$ The main virulence factor of C. ulcerans and C. pseudotuberculosis is phospholipase $\mathrm{D}(p l d)$. In addition, these bacteria which are inserted by a particular bacteriophage can produce diphtheria toxin (DT) and cause disease in humans with clinical characteristics which simulate diphtheria caused by Corynebacterium diphtheria. $(19,20)$ Moreover, C. ulcerans is used as an indicator of the success of the diphtheria surveillance program.(21) In United Kingdom, the cases of diphtheria caused by $C$. ulcerans as many as or even more than diphtheria caused by $C$. diphtheriae.(22) In addition, diphtheria caused by C. ulcerans is also found in other countries, such as, Germany, Japan, France, and Brazil. (3,23-25) Diphtheria caused by C. ulcerans found in many developed countries with good immunization coverage. This is probably because the immunization has not full protection against $C$. ulcerans. It is proved by the fact that about $75 \%$ of cases occur in individuals with a history of immunization.(3)

Detection and identification of $C$. ulcerans and $C$. pseudotuberculosis in the laboratory can be performed with conventional method or Polymerase Chain Reaction (PCR) assay. The PCR assay has several advantages because it is relatively rapid and easy for result interpretation. The PCR can also be used for the identification of bacterial species and its toxigenicity simultaneously.(26,27) Several previous studies have reported the success of PCR assay for detection and identification of C. ulcerans and C. pseudotuberculosis. The pld, 16S rRNA and rpoB genes were usual gene used as markers or target genes for the identification of genus and species. Conversely, the tox gene used as a target gene for the identification of bacterial toxigenicity.(27-29) Based on the bioinformatics reviews, diphtheria toxin repressor $(d t x R)$ gene is more conserve than pld gene and more specific than $16 S r R N A$ gene. This study aimed to describe the $d t x R$ gene profile as a new marker for C. ulceran and C. pseudotuberculosis for the PCR assay. Moreover, this is the first study which in $d t x R$ gene was used as a marker to identify C. ulcerans and C. pseudotuberculosis.

\section{Methods}

\section{Sample}

The DNA sequences of $d x R$, pld and $16 S$ rRNA genes of 10 C. ulcerans dan 35 C. pseudotuberculosis complete genome are registered in GenBank (http://www.ncbi.nlm. nih.gov/) (May, 2016) analyzed in this study. All of complete sequence (from start codon until stop codon) in FASTA format were copied and grouped into six 'txt files' based on gene and bacterial species. There were six files content DNA sequences of $d t x R$, pld and $16 S$ rRNA genes for each species (C. ulcerans and C. pseudotuberculosis). On the other side, the reference strains of $C$. ulcerans NCTC 12077, C. diphtheriae (NCTC 3984) and synthetic DNA of $d t x R$ gene of C. pseudotuberculosis (gBlock Gene fragments, Ref No. 99284102, Integrated DNA Technologies) were used as a sampel in the PCR assay to identify both species (C. ulcerans and C. pseudotuberculosis) with $d t x R$ gene as a marker. All of the isolates were cultured on blood agar plate and incubated at $37^{\circ} \mathrm{C}$ in 24 hours. Bacterial cells were harvested and kept in cryo tube contained $500 \mathrm{~mL}$ aquadest. The synthetic gene sequences of $d t x R C$. pseudotuberculosis were synthetized based on $d t x R$ gene sequences of $C$. pseudotuberculosis 31 that available in GenBank.

\section{DNA Sequences Analysis}

The conserved gene was determined by ratio of amount of the mutation compare with the amount of nucleotide within the gene sequences. The alignment of DNA sequence to identify base mutation in this study used BioEdit software. The specifity of the gene was determined by comparing DNA sequences of $d t x R$ or pld or $16 S$ rRNA gene of the targeted bacteria (C. ulcerans and C. pseudotuberculosis) to DNA sequences of $d t x R$ or pld or $16 S r R N A$ or other gene of the non-targeted bacteria. The analysis of DNA sequence was performed using basic local alignment sequence type (BLAST) online.

\section{PCR Primer Design}

The sensitivity and specificity of PCR are determined by the accuracy of the sequences of the primer used. Hybridization target of the primer must be located in a specific and conserve area to avoid the failures of amplifications.(30) The PCR primers can be designed and predicted by modeling using the bioinformatics tools.(31) In this study, PCR primers were design by semi automatic method based on DNA sequence allignment of $d t x R$ gene of 10 C. ulcerans, 35 C. pseudotuberculosis and 34 C. diphtheriae. The PCR primer candidates were tested by PerlPrimer to predict its feasibility. The further analysis by primer BLAST was done to determine its sensitifity and specificity. The selected primer sequences were ordered in the provider company (Integrated DNA Technologies, Iowa, USA). 


\section{PCR Assay}

Bacterial DNA extraction carried out by boiling method as described previously.(32) PCR condition was defined by optimized multiplex reaction, as well as PCR reaction content. The PCR reaction compounds $12.5 \mathrm{uL}$ My Taq HS Red Mix (Bioline), 2.5 uL PCR primer (2 pairs), 7 $\mathrm{uL}$ ddH2O, and $3 \mathrm{uL}$ DNA template. The PCR condition that used in this study were initial denaturation $95^{\circ} \mathrm{C}$ for 5 minutes followed by 30 cycle denaturation $95^{\circ} \mathrm{C}$ for 15 seconds, annealing $60^{\circ} \mathrm{C}$ for 15 seconds and extention $72^{\circ} \mathrm{C}$ for 30 seconds. PCR product was separated by gel electrophoresis in 2\% agarose gel using GelRed (Biotium) as the DNA dye. Visualisation and result analyse using Gel Doc XR plus (Biorad).

\section{Results}

\section{DNA Sequence Analysis}

Specificity of a gene is determined by DNA sequence similarities of targeted and non-targeted genes. Comparison of specificity of pld, $16 \mathrm{~S} r R N A$, and $d t x R$ genes (Table 1) show that the $d t x R$ and pld genes have good specificities on each targeted bacterias (C. ulcerans and C. pseudotuberculosis) as a marker for PCR assay. This condition was characterized by the absence of non-targeted DNA sequences with high similarity ( $>95 \%$ ). On the other hand, 16SrRNA gene of C. ulcerans or C. pseudotuberculosis have high similarities $(>95 \%)$ with the DNA sequences of four non-targeted bacteria species (C. diphtheriae, Corynebacterium vitaeruminis, Corynebacterium mustelae, and Corynebacterium freiburgense).
The number of the nucleotide bases mutation could be used to estimate the conserved gene. Comparison of the conserved gene between $d t x R$, pld, and $16 S$ rRNA genes of C. ulcerans (Supplement 1) show that DNA mutations up to 45 of $681(6.6 \%)$ nucleotide bases that arrange dtxR gene. Most mutations occur in C. ulcerans 131002 and FRC11 strains, therefore these strains can be assumed as if they were different clonals of $C$. ulcerans in general. If the analysis is performed by splitting C. ulcerans into two categories (right column), DNA mutations only occur 4 of $681(0.6 \%)$ nucleotide bases in $d t x R$ gene. Moreover, DNA mutations up to 60 of 924 (6.5\%) nucleotide bases that arrange pld gene. In addition, C. ulcerans 131002 and FRC11 strains were categorized into different clonal, however the number of mutation was slightly different since the DNA mutations spread throughout most of the strain. The 16S rRNA gene is the most concerved gene that analyzed. DNA mutation (deletion and substitution) of gene occurs only at 5 of 1491 (0.3\%) nucleotide bases that arrange the 16S rRNA gene.

Comparison of the conserved gene between $d t x R$, pld, and 16S rRNA genes of C. pseudotuberculosis (Supplement 2) show that DNA mutations only 6 of $681(0.9 \%)$ nucleotide bases that arrange the $d t x R$ gene. Moreover, DNA mutations (deletion, insertion and substitution) were found at 7 of $1491(0.005 \%)$ nucleotide bases that arrange the $16 \mathrm{~S}$ rRNA gene. In contrast, there were DNA mutations at 33 of 924 $(3.6 \%)$ nucleotide bases that arrange the $p l d$ gene.

\section{Primer Design}

The PCR primers targeted $d t x R$ gene of $C$. ulcerans and C. pseudotuberculosis were designed semi-automatic (manually) using Bioedit and perlPrimer programs.

Table 1. Specificity of $d t x R$ gene, pld gene and $16 S r R N A$ gene .

\begin{tabular}{|c|c|c|}
\hline Gene & $\begin{array}{c}\text { Interspecies } \\
\text { Identity }>95 \%\end{array}$ & Species \\
\hline \multicolumn{3}{|l|}{ C. ulcerans } \\
\hline$d t x R$ & 0 & - \\
\hline pld & 0 & - \\
\hline $16 S r R N A$ & 5 & $\begin{array}{c}\text { C. pseudotuberculosis, C. diphtheriae, } \\
\text { C. vitaeruminis, C. mustelae, C. freiburgens * }\end{array}$ \\
\hline \multicolumn{3}{|c|}{ C. pseudotuberculosis } \\
\hline$d t x R$ & 0 & - \\
\hline pld & 0 & - \\
\hline $16 S r R N A$ & 5 & $\begin{array}{l}\text { C. ulcerans, } C \text {. diphtheriae, } C \text {. vitaeruminis, } C \text {. } \\
\text { mustelae, } \text { C. freiburgense } *\end{array}$ \\
\hline
\end{tabular}


Table 2. Optional PCR primer sequences targeted $d t x R$ gene for $C$. ulcerans dan $C$. pseudotuberculosis identification .

\begin{tabular}{|c|c|c|c|c|}
\hline $\begin{array}{l}\text { Primer } \\
\text { Number }\end{array}$ & Primer Name & Sequences & Targeted Gene & PCR Product \\
\hline \multirow[t]{2}{*}{1} & Dtxru 1_F & TAGTCGCATCCGACCGCAGC & & \\
\hline & Dtxru 1_R & GGGAAACACCGAGTTCGTCTAAACC & dtxR C. ulcerans & $261 \mathrm{bp}$ \\
\hline \multirow[t]{3}{*}{2} & Dtxru 2_F & GACCGCAGCCTTCAAATGACA & & \\
\hline & Dtxru 2a_R & CTTGCCGGGCTCTTCCTTT & dtxR C. ulcerans type $1^{*}$ & $276 \mathrm{bp}$ \\
\hline & Dtxru 2b_R & CGCATCGATAAGCGCCTGA & dtxR C. ulcerans type $2 * *$ & $381 \mathrm{bp}$ \\
\hline \multirow[t]{2}{*}{3} & Dtxrp 1_F & GGGCTCGTTGTAGTTGCGTCT & & \\
\hline & Dtxrp 1_R & GGCATGCTTCATCGTGCACC & dtxR C.pseudotuberculosis & $154 \mathrm{bp}$ \\
\hline \multirow[t]{3}{*}{4} & Dtxrup 1a_F & GTTTAGACGAACTCGGTGTTTCCC & dtxR C. ulcerans & $271 \mathrm{bp}$ \\
\hline & Dtxrup 1b_F & ACGAAGTAGAGCGGCGGCTT & dtxR C.pseudotuberculosis & $343 \mathrm{bp}$ \\
\hline & Dtxrup 1_R & TCGATTCGTACTGCGTGAGCTAGG & & \\
\hline \multirow[t]{4}{*}{5} & Dtxrup 2_F & a $a$ CCCAGGGACGTACGGATC & & \\
\hline & Dtxrup 2a_R & TTCCAGGCACTTATCGACGCA & dtxR C. ulcerans type $1^{*}$ & $140 \mathrm{bp}$ \\
\hline & Dtxrup 2b_R & ACGAAGTAGAGCGGCGGCTT & dtxR C. ulcerans type $2^{* *}$ & 199 bp \\
\hline & Dtxrup 2c_R & TCTTCGATTCGTACTGCGTGAGC & dtxR C.pseudotuberculosis & $346 \mathrm{bp}$ \\
\hline
\end{tabular}

PCR primer pairs which target dtxR gene (Table 2) could be used for the identification of $C$. ulcerans and $C$. pseudotuberculosis. Primer pair number 1 and 2 could be used for detection and identification of C. ulcerans, whereas primer pair number 3 can be used for the detection of C. pseudotuberculosis in a monoplex PCR reaction. Identification of the bacteria $(C$. ulcerans and $C$. pseudotuberculosis) at the same time in a multiplex PCR reaction could use combinations of primer pair's number 1 and 3, number 2 and 3, number 4 or number 5 only.

\section{PCR Assay}

The primer application in PCR assay for the identification of C. ulcerans and C. pseudotuberculosis was performed by multiplex reactions using two pairs of primers, i.e., primer pairs number 1 (dtxru 1_F and dtxru 1_R) and primer number 3 (dtxrp 1_F and dtxrp_1R).

The PCR primer number 1 and 3 were applicable to be performed on multiplex PCR assay for the identification of C. ulcerans and C. pseudotuberculosis correctly without mispriming, misamplification, and misidentification in $d t x R$ genes of $C$. diphtheriae (Figure 1). The band $154 \mathrm{bp}$ (Line 2) match with the length of PCR products generated by the primer number 3, as a marker for C. pseudotuberculosis. The band $261 \mathrm{bp}$ (Line 3) match with the length of PCR product generated by primer pairs number 1 , as a marker for C. ulcerans. Furthermore, the band was not visible on Line 4 (C. diphtheriae) as well as Line 5 (negative control). Interpretation of the results was quite easy because PCR products had different length. It was important to examine the $d t x R$ gene as a marker for $C$. ulcerans and C. pseudotuberculosis, so it was not only meets the requirements for bioinformatics analysis but also applicable for PCR assay. However, several other primer pairs have only tested using bioinformatics as one of the limitations of this study. Another limitation of this study was the small number of samples tested.

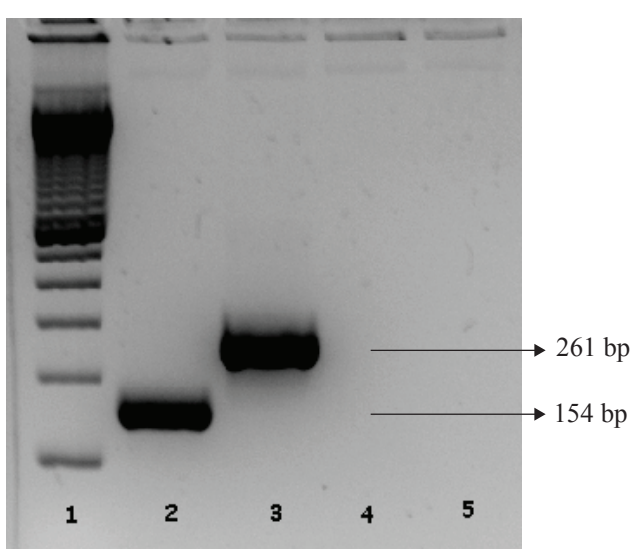

Figure 1. PCR Assay for the identification of $C$. ulcerans and C. pseudotuberculosis. Line 1: 100 bp DNA ladder; Line 2: C. pseudotuberculosis; Line 3: the synthetic DNA of $d t x R$ gene of C. ulcerans; Line 4: C. diphtheriae; Line 5: negative control (ddH2O) 


\section{Discussion}

The pld and 16S rRNA genes analyzed in this study because the genes are commonly used for identification of the targeted sample (C. ulcerans and C. pseudotuberculosis). Moreover, $d t x R$ gene analyzed because the gene would be used as a new marker in this study. Meanwhile, $d t x R$ synthetic gene was used as a sample in PCR assay to replace the position of $d t x R$ gene of $C$. pseudotuberculosis as the targeted sample. Synthetic gene could be used as an alternative positive control in PCR assay if positive control is hardly to obtain.(33) C. diphtheriae was used as a sample to test the specificity of PCR assay because it has a closed relationship with both of the target bacteria in one Genus Corynebacterium.(1) Additionally, $d t x R$ gene of $C$. diphtheriae was similar to $d t x R$ genes of $C$. ulcerans and $C$. pseudotuberculosis based on BLAST analysis. Therefore, mispriming may occur if the PCR primers are not specific.

The PCR sensitivity will decrease when a DNA mutation occurs in the location where a primer bonds. This condition may cause a failure of amplification (false negative), especially when the mutation locate in the 3'-end of a primer.(34) Conversely, mispriming and misamplification can occur when the non-target DNA has similar sequences to the target gene. This will increase the risk of false positive in the PCR assay.(35) Table 1, Supplement 1 and Supplement 2 show that $d t x R$ genes of $C$. ulcerans and $C$. pseudotuberculosis have specific and conserved sequences that capable to be the target gene in the PCR assay. Spesificity of $d t x R$ gene is comparable to pld genes, but more specific than $16 S$ rRNA gene. On the contrary, the conserved sequence of $d t x R$ gene is comparable to the $16 \mathrm{~S}$ $r R N A$ gene but more conserved than pld gene. The significant differences in $d t x R$ gene sequences of C. ulcerans 131002 and FRC11 strains can be used to perform strain distinction. C. ulcerans FRC11 strain was isolated from a 78 years-old patient with infection in the leg in France. Firstly, this strain was identified as C. pseudotuberculosis. The analysis of $d t x R$ gene sequence also demonstrated that the mutations occured resembling $d t x R$ gene of $C$. pseudotuberculosis. $C$. ulcerans 131002 strain isolate was found in humans as well, unfortunately there was no specific data about the country of origin and year of isolation. However, several data stated that the sequencing projects of both strains (C. ulcerans 131002 and FRC11 strains) were performed in the same laboratory, in Brazil. Therefore, there is possibility that both are derived from the same clone.(36,37)
All primer pairs have tested using perlPrimer and BLAST. The analysis using perlPrimer did not reveal any 'run' and 'repeat' with Tm difference not more than $3^{\circ} \mathrm{C}$. The analysis using BLAST showed that the primers were specific, there was no mismatching with non-targeted DNA detected. In addition, the results were consistent with our predictions that the primers could match with the entire samples (11 C. ulcerans strains and 64 C. pseudotuberculosis strains). In the primer number 5 (dtxrup 2_F), modification of 2 bases at the end of 5' (italic) was performed to decrease GC content and the risk of primer-dimer bonds. This modification has predicted that would not affect the sensitivity of the assay because it was located at the 5 '-end.(38)

C. ulcerans and C. pseudotuberculosis has been proved may cause disease in humans with the transmission through animals (zoonotic).(39) The identification of both bacteria can be used to facilitate the investigation of close contacts of diphtheria patients in the investigation of disease transmission. In cases of diphtheria caused by $C$. ulcerans and C. pseudotuberculosis, the investigation of disease transmission will be more focused on animals in contact with patients. Conversely, in cases of diphtheria caused by $C$. diphtheriae, the investigation for transmission of the disease will be more focused on people in contact with the patient.

Nevertheless, the person-to-person transmission in $C$. ulcerans and C. pseudotuberculosis ingection and animalto-person transmission in $C$. diphtheriae infection still can not be excluded.(40) The rapid and accurate identification for the cause of diphtheria by multiplex PCR assay will improve patient's prognosis and prevent the disease spreading to the environment.

This study was a pilot project designed to further development of diagnosis of $C$. ulcerans and $C$. pseudotuberculosis using PCR assay. The results of this study might complement the achievements accomplished by the researchers previously for the same purpose. $(26,27,29)$ The fundamental difference lay in the selection of the target genes. In this study, $d x R$ gene (single gene) was used as a marker or target gene, while previous studies used $p l d$, rpoB and $16 S$ rRNA, either singly or collectively. The results showed several advantages of $d t x R$ gene compared to other genes as markers of C. ulcerans and C. pseudotuberculosis. In addition, $d t x R$ gene was generally used only as a marker for the detection and identification of $C$. diphtheriae. To our knowledge, this is the first report on the use of $d t x R$ gene as a marker or target gene in the identification of $C$. ulcerans and C. pseudotuberculosis using PCR assay. 


\section{Conclusion}

This study showed that $d t x R$ gene could be used as a marker to identify C. ulcerans and C. pseudotuberculosis by PCR assay.

\section{Acknowledgment}

We would like to thank to all of friends in Bacteriology Laboratory, Laboratorium Prof. dr. Sri Oemijati.

\section{References}

1. Venezia J, Cassiday PK, Marini RP, Shen Z, Buckley EM, Peters Y, et al. Characterization of Corynebacterium species in macaques. J Med Microbiol. 2012; 61:1401-8.

2. Wagner KS, White JM, Crowcroft NS, De Martin S, Mann G, Efstratiou A. Diphtheria in the United Kingdom, 1986-2008: the increasing role of Corynebacterium ulcerans. Epid Infec. 2010; 138: 1519-30.

3. Dias AASO, Santos LS, Sabbadini PS, Santos CS, Silva FCJr, Napoleao F, et al. Corynebacterium ulcerans diphtheria: an emerging zoonosis in Brazil and worldwide. Rev Saude Publica. 2011; 45: 1176-91.

4. Katsukawa C, Kawahara R, Inoue K, Ishii A, Yamagishi H, Kida K, et $a l$. Toxigenic Corynebacterium ulcerans isolated from the domestic dog for the first time in Japan. Jpn J Infect Dis. 2009; 62: 171-2.

5. Marini RP, Cassiday PK, Vanezia J, Shen Z, Buckley EM, Peters Y, et al. Corynebacterium ulcerans in Ferrets. Emerg Infect Dis. 2014; 20: 159-61.

6. Berger A, Huber I, Merbecks SS, Ehrhard I, Konrad R, Hörmansdorfer $\mathrm{S}$, et al. Toxigenic Corynebacterium ulcerans in woman and cat. Emerg Infect Dis. 2011; 17: 1767-9.

7. Eisenberg T, Mauder N, Contzen M, Rau J, Ewers C, Schlez K, et al. Outbreak with clonally related isolates of Corynebacterium ulcerans in a group of water rats. BMC Microbiology. 2015; 15: 42. doi: 10.1186/s12866-015-0384-x.

8. Hirai-Yuki A, Komiya T, Suzaki Y, Ami Y, Katsukawa C, Takahashi M, et al. Isolation and characterization of toxigenic Corynebacterium ulcerans from 2 closed colonies of Cynomolgus Macaques (Macaca fascicularis) in Japan. Comp Med. 2013; 63: 272-6.

9. Katsukawa C, Komiya T, Yamagishi H, Ishii A, Nishino S, Nagahama $\mathrm{S}$, et al. Prevalence of Corynebacterium ulcerans in dogs in Osaka, Japan. J Med Mocrobiol. 2012; 61: 266-73.

10. Zavoshti FR, Khoojine ABS, Helan JA, Hassanzadeh B, Heydari AA. Frequency of caseous liphadenitis (CLA) in sheep slaughtered in an abattoir in Tabriz: comparison of bacterial culture and pathological study. Comp Clin Path. 2012; 21: 667-71.

11. Alharbi KB. Bacterial isolates from visceral abscesses of sheep at Qassim, Saudi Arabia. Afr J Microbiol Res. 2011; 5: 5622-7.

12. Saeed EM, Alharbi KB. Morel's disease and caseous lymphadenitis: a literature review with special reference to Saudi Arabia. IOSRJAVS. 2014; 7: 76-86.

13. Hassan SS, Schneider MP, Ramos RT, Carneiro AR, Ranieri A, Guimarães LC, et al. Whole-genome sequence of Corynebacterium pseudotuberculosis strain Cp162, isolated from camel. J Bacteriol. 2012; 194: 5718-9.

14. Syame SM, Hakim AS, Hedia RH, Marie HSH, Selim SA. Characterization of virulence gene present in Corynebacterium pseudotuberculosis strains isolat from bufallo. Global Veterinaria. 2013; 10: 585-91.

15. Oliveira M, Barroco C, Mottola C, Santos R, Lemsaddek A, Tavares $\mathrm{L}$, et al. First report of Corynebacterium pseudotuberculosis from caseous lymphadenitis lesions in Black Alentejano pig (Sus scrofa domesticus). BMC Veterinary Research. 2014; 10: 218. doi: 10.1186/s12917-014-0218-3.

16. Heggelund L, Gaustad P, Håvelsrud OE, Blom J, Borgen L, Sundset $\mathrm{A}$, et al. Corynebacterium pseudotuberculosis pneumonia in a veterinary student infected during laboratory work. OFID. 2015 2: ofv053. doi: 10.1093/ofid/ofv053.

17. Bastos BL, Portela RWD, Dorella FA, Ribeiro D, Seyfert N, Castro TLP, et al. Corynebacterium pseudotuberculosis: Immunological responses in animal model and zoonotic potential. J Clin Cell Immunol. 2012; S4: 005. doi:10.4172/2155-9899.S4-005.

18. Stefańska I, Gierynska M, Rzewuska M, Binek M. Survival of Corynebacterium pseudotuberculosis within macrophages and induction of phagocytes death. Pol J Vet Sci. 2010; 13: 143-9.

19. Hacker E. Characterization of Virulence of Corynebacterium ulcerans [Dissertation]. Erlangen: der Friedrich-Alexander-Universität Erlangen-Nürnberg; 2016.

20. Wagner KS, White JM, Lucenko I, Mercer D, Crowcrft NS, Neal S, et al. Diphtheria in the postepidemic period, Europe, 2000-2009. Emerg Infect Dis. 2012; 18: 217-25.

21. Wagner KS, Zakikhany K, White JM, Amirthalingam G, Crowcroft NS, Efstratiou A. Diphtheria surveillance. In: Burkovski A, Editor. Corynebacterium diphtheriae and Related Toxigenic Species. New York: Springer; 2014. p.207-24.

22. Wagner KS, White JM, Crowcroft NS, de Martin S, Mann G, Efstratieau A. Diphtheria in United Kingdom, 1986-2008: The increasing role of Corynebacterium ulcerans. Epidemiol Infect. 2010; 138: 1519-30.

23. Eisenberg T, Kutzer P, Peters M, Sing A, Contzen M, Rau J. Nontoxigenic tox-bearing Corynebacterium ulcerans infection among game animals, Germany. Emerg Infect Dis. 2014; 20: 44852.

24. Komiya T, Seto Y, De Zoysa A, Iwaki M, Hatanaka A, Tsunoda A, et $a l$. Two Japanese Corynebacterium ulcerans isolates from the same hospital: Ribotype, toxigenicity and serum antitoxin titre. J Med Microbiol. 2010; 59: 1497-504.

25. Vandentorren SV, Guiso N, Badell E, Boisrenoult P, Micaelo M, Troche G, et al. Toxigenic Corynebacterium ulcerans in a fatal human case and her feline contacs, Frence, March 2014. Euro Surveill. 2014; 19: 20910.

26. Nassar AFC, Daniel GT, Ruiz R, Miyashiro S, Scannapieco EM, Neto JS, et al. Diagnostic comparison of Corynebacterium pseudotuberculosis through microbiological culture and PCR in sheep samples. Arq Inst Biol. 2015; 82: 1-6

27. Torres LDFC, Ribeiro D, Hirata R Jr, Pacheco LGC, Souza MC, Ribeiro MG, et al. Multiplex polymerase chain reaction to identify and determine the toxigenicity of Corynebacterium spp with zoonotic potential and an overview of human and animal infections. Mem Inst Oswaldo Cruz. 2013; 108: 272-9.

28. Sing A, Berger A, Schneider-Brachert W, Holzmann T, Reischl $\mathrm{U}$. Rapid detection and molecular differentiation of toxigenic Corynebacterium diphtheriae and Corynebacterium ulcerans strains by Light Cycler PCR. J Clin Microbiol. 2011; 49: 2485-9. 
29. Pacheco LGC, Pena RR, Castro TLP, Dorella FA, Bahia RC, Carminati $\mathrm{R}$, et al. Multiplex PCR assay for identification of Corynebacterium pseudotuberculosis from pure culture and for rapid detection of this pathogen in clinical samples. J Med Microbiol. 2007; 56: 480-6.

30. Cassiday PK, Pawloski LC, Tiwari T, Sanden GN, Wilkins PP. Analysis of toxigenic Corynebacterium ulcerans strains revealing potential for false-negative real-time PCR results. J Clin Microbiol. 2008; 46: 331-3.

31. Thornton B, Basu C. Real-time PCR (qPCR) primer design using free online software. Biochem Mol Biol Educ. 2011; 39: 145-54.

32. Pimenta FP, Hirata R, Rosa ACP, Milagres LG and MattosGuaraldi AL. A multiplex PCR assay for simultaneous detection of Corynebacterium diphtheriae and differentiation between nontoxigenic and toxigenic isolates. J Med Microbiol. 2008; 57:1438-9.

33. Wang B, Steain MC, Dwyer DE, Cunningham AL, Saksena NK. Synthetic ion oligonucleotides to generate artificial templates for use as positive controls in molecular assays: drug resistance mutations in influenza virus as an example. Virol J. 2011; 8: 405. doi: 10.1186/1743-422X-8-405

34. Lemmon GH, Gardner SN. Predicting the sensitivity and specificity of published real-time PCR assay. Ann Clin Microbiol Antimicrob. 2008; 7: 18. doi: 10.1186/1476-0711-7-18.
35. Wollants E, Van Ranst M. Detection of false positives with a commonly used Norovirus RT-PCR primer set. J Clin Virol. 2013; 56: $84-5$.

36. de Jesus Benevides L, Viana MV, Mariano DC, de Souza Rocha F, Bagano PC, Folador EL, et al. Genome sequence of Corynebacterium ulcerans strain FRC11. Genome Announc. 2015; 3: e00112-15. doi: 10.1128/genomeA.00112-15.

37. Guimarães LC. Comparative Genomics and Pan-genomic Study of Genus Corynebacterium [Dissertation]. Belo Horizonte: Universidade Federal de Minas Gerais; 2015.

38. Boyle B, Dallaire N, MacKay J. Evaluation of the impact of single nucleotide polymorphisms and primer mismatches on quantitative PCR. BMC Biotechnology. 2009; 9: 75. doi: 10.1186/1472-6750-975.

39. Meinel DM, Konrad R, Berger A, König C, Schmidt-Wieland $\mathrm{T}$, Hogardt $\mathrm{M}$, et al. Zoonotic transmission of toxigenic Corynebacterium ulcerans strain, Germany, 2012. Emerg Infect Dis. 2015; $21: 356-8$

40. Hall AJ, Cassiday PK, Bernard KA, Bolt F, Steigerwalt AG, Bixler D, et al. Novel Corynebacterium diphtheriae in domestic cats. Emerg Infect Dis. 2010; 16: 688-91. 